\title{
The out-and-about consultation
}

I find that in my consulting rooms I am on home territory and that there is some reasonable control over the events that occur with my patients. In the rooms there is all the equipment, files and backup that I need. This all changes once I step outside the door into the street outside. When I am out-and-about in the community, either socially or on a shopping trip or to play sport, I leave a lot of the control and firewalls behind.

It is in these situations that we are vulnerable to the CarPark consultation or the "I'm-so-glad-I've-caught-you" consultation as well as "Corridor Consultations" by the staff or patients when I am visiting the hospital.

One of my out-and-about trips occurred when my son was home from university and we went shopping together in our local Pick 'n Pay. At the end of our shopping he recorded that I had done three consultations by the time we left the shopping centre. One was in the vegetable department (a rash on a leg in the section where the broccoli was on special), another in the aisle that contained the tea, coffee and sugar and a final one in the queue while waiting for the cashier.

One of the other great dangers of being out-and-about are dinner parties or similar social occasions: “Doctor, could I ask your opinion about my niece, father, friend...," always gets the red lights flashing. It may be seeking confirmation of a diagnosis that has been made or a criticism of treatment that has been given. At this point I have usually had a couple of glasses of Pinotage Special Edition neuronal release therapy. I am then in an expansive mood as a world authority on all illnesses known to man.

The golden rule here is to try to fermez la bouche (close the mouth). "Never believe what a patient tells you to the detriment of a brother physician" said Sir William Osler "even though you may think it to be true". The right answer here is to comment carefully that it is very difficult to give an opinion without knowing the full case history. Apparently up to fifty percent of legal cases against doctors are initiated due to comments by other doctors, nurses or medical personnel.

The other alarm bells should start ringing when the statement is "Dr Smith said....," or "the specialist said....,." What is about to follow is often the second-hand interpretation of what they thought the doctor said. So rule number two is a similar caution to Sir William Osler's advice but is subtly different. We should not always believe what a patient says a doctor told them whether it sounds right or wrong. You then apply rule three.

Rule three is "I think that is my phone ringing, will you kindly excuse me".

There are other types of out-and-about consultations apart from dinner table conversations.

Many moons ago I was once doing a rural clinic in the Injasuti Valley in the Drakensberg mountains when someone came running to the clinic to say that a patient was giving birth in the field on the other side of the fence by the Injasuti river. She had been in labour since the early morning and had walked down from the top of the valley to the clinic but did not quite get to us. I went out and climbed through the fence and found her lying in the dry grass by the river. To my dismay there were two little feet already presenting. It was going to be a breech delivery.

It is in moments like these that I have wondered if the practice of medicine was a wise choice and that perhaps I would have had a more peaceful life as a bank clerk or an accountant. I asked the nurse who had come with me to go back and bring some artery forceps and ties for the cord but I would not be able to suction the baby or do much resuscitation if it was compromised. I calmed down to a panic and the mother then gave a couple of pushes and I managed to deliver the arms. Then with my left hand around the neck and my right index finger in the baby's mouth the mother pushed the baby slowly out. The baby cried heartily. The mother smiled. I looked up. The midday sun was dancing in flashes of light on the surface of the Injasuti river as it flowed slowly by. A fine pale blue sky stretched for miles into the far horizons of the mountains. Life was beginning again in an African world.

Chris Ellis is a family physician in Pietermaritzburg, KwaZulu-Natal

E mail: cristobalellis@gmail.com 